\title{
Implementing Six Sigma via Management by Objectives Strategy: An Empirical Study in Taiwan
}

\author{
Jung-Lang Cheng* \\ Department of Industrial Engineering and Management, Cheng Shiu University, Taiwan \\ *Corresponding author: ChengLL@csu.edu.tw
}

\begin{abstract}
The paper reviews the related literature on Six Sigma and management by objectives (MBOs), and then proposes the framework of implementing Six Sigma via MBOs strategy. An empirical study on the experience an aerospace industry parts-making in Taiwan which implementing the framework in are explored. This paper provides a comprehensive perspective of three steps on the using MBOs methodology to implement Six Sigma which are to build the organizational consensus, formulate Six Sigma strategy and to integrate action workout plan with Six Sigma project. According to the implementing experience in Taiwan, lies in conducting a comparative study on the improvement stages of Six Sigma implementation project. The paper will be valuable for quality professionals and management personnel in the aerospace related industry.
\end{abstract}

Keywords: six sigma, DMAIC, business strategy, MBO, aerospace industry

Cite This Article: Jung-Lang Cheng, "Implementing Six Sigma via Management by Objectives Strategy: An Empirical Study in Taiwan.” Journal of Business and Management Sciences, vol. 5, no. 2 (2017): 35-41. doi: 10.12691/jbms-5-2-2.

\section{Introduction}

The Six Sigma has become the most prominent trend in quality management which not only for manufacturing and service industries, but also for non-profit organizations and government institutes [1,2]. Kumar et al. (2007) [3] presented a case on application of Six Sigma problem-solving methodology in manufacturing process to identify the parameters causing casting defects and to control these parameters. Krishna et al. (2008) [4] presented a case study illustrating how a multinational Indian corporation was able to successfully implement Six Sigma principles to improve its manufacturing operations. Azis, \& Osada (2010) [5] confirms that Six Sigma has a positive and comprehensive impact on changing the management system. Six Sigma have been harmonizing and synergizing people and processes by establishing a clear linkage among critical factors. If Six Sigma implementation wants to be a successful, Six Sigma efforts must integrate with existing business strategy initiatives, and key performance measures [6].

Management by objectives (MBOs) was originated in the 1950s by Peter Drucker in his classic, The Practice of Management and has endured in some forms into current practice [4]. A MBOs process converts overall objectives into specific objectives down to organizational units and individual members. This concept appears to be closely related to performance management techniques still in use at many organizations.

However, existing studies are often little concerned about linking intension of MBO and Six Sigma. Could MBO apply in Six Sigma implementation effectively? The paper organically makes integrating MBOs with Six
Sigma to explore the system should be paid attention to during the process of implementation. The paper seeks to the following goals:

(1) The literature review reveals MBO and Six Sigma are a dichotomy, i.e. MBOs is separate from the Six Sigma system, with no connecting points of contact between the two systems. However, MBOs evolution is a strategy process which can integrate Six Sigma system to gain business performance. The issue of using MBOs principle to implement Six Sigma needs to be explored.

(2) In most literature reviews, experiences of implementing Six Sigma systems are related to making use of a variety of management systems, but no MBOs practice. Accordingly, the question of how can the strategic MBOs goals be communicated to lower departments in the organization, and further deploy the strategic goals to the Six Sigma projects and organize the project teams must be considered.

After considering the general understanding of MBOs and Six Sigma, The paper investigates the case study of using MBOs principle to implement Six Sigma of a Taiwanese company. The paper describes its method of research and presents the findings, Conclusions and implications for both practice and theory meanings will end the paper.

\section{A review of the Literature on MBO and Six Sigma}

\subsection{Six Sigma Methodology}

Pande et al. (2000) [7] indicated that the Six Sigma system is a set of management-oriented concepts, and that 
implementing the system requires not only the application skills of quality management skills, but also the development of an appropriate business strategy. Six Sigma programs are designed to achieve a competitive advantage, and thus should be clearly linked to business priorities, as reflected by a firm's strategic and action plans [8]. Pearson (2001) [9] indicated that the key to Six Sigma success is to optimize overall business results by balancing cost, quality, features and availability considerations for products and their production into an optimum business strategy. The process of business management is one in which the links between a firm's quality objectives and its business strategy should be identified [10]. Chatterjee (2003) [11] noted that organizations should be designed, led and managed so that it is easy for customers to do business with them, and that it is necessary to create an environment that helps employees serve customers. Six Sigma is also a business strategy and systematic methodology, the use of which often leads to breakthroughs in profitability through significant gains in product/service quality, customer satisfaction and productivity.

A Six Sigma business strategy relies on statistical tools and specifically designed processes and methods, in order to achieve measurable goals to pursue increasing efficiency and productivity, reducing waste and enhancing products and processes. Antony et al. (2005) [12] stated that the most important factors for successful Six Sigma implementation are management involvement and participation, linking Six Sigma to customers and to the business strategy of the organizations. From this perspective the decision rights to initiate a project are allocated to senior managers, and Six Sigma can thus help achieve them to carry out appropriate strategies by selecting strategically related projects [13]. The potential of Six Sigma to help companies formulate and deploy a business strategy and bring about broad transformational change means that it can be seen as a high order leadership approach, philosophy, and methodology for change.

\subsection{DMAIC Methodology}

The basic statistical tools used in five phases of DMAIC methodology helps identify, quantify and eliminate the root cause of waste or rejections and sustain the improved performance of the production line with well-executed control plans in future [14]. The DMAIC methodology is an effective improvement method which linking key statistical tools [15]. Six Sigma DMAIC methodology provides a structured framework for solving business problems by assuring correct and effective process execution [16]. In each step of the DMAIC methodology, teams must use self-diagnosis to fulfill the goals of each phase. When all key processes within a business are completed for these five steps, the Six Sigma qualities can be reached. Jirasukprasert et al. (2014) [17] presents an industrial case which demonstrates how the application of Six Sigma and DMAIC can help manufacturing organizations to achieve quality improvements in their processes and thus contribute to their search for process excellence. DMAIC methodology also requires total employee involvement to complete the cycle of process improvement management. To ensure the success of a DMAIC methodology of Six Sigma project effort, Bryne (2003) [18] proposed that the top corporate leaders must champion the active support and engagement of all business process owners in Six Sigma project implementation down the line.

\subsection{Management by Objectives}

MBOs are to set the objectives, and allow employee empowerment about how to achieve 'freedom to challenge everything; continuous training and development on the job; knowledge of, and faith in, the organization's mission; and the ability to achieve and see results' [19]. An MBO process converts overall objectives into specific objectives down to organizational units and individual members. This concept appears to be closely related to performance management techniques still in use at many organizations. Robbins (1997) [20] defined MBOs as a system in which specific performance objectives are jointly determined by subordinates and their superiors; progress toward objectives is periodically reviewed and rewards are allocated on the basis of this progress. MBOs were developed and utilized in planning and establishing this evaluation system for performance focused on satisfying customers, both internal and external, which leads to the best value for investing in organization's team [21].The intent of MBOs is to improve organizational performance by aligning goals and subordinate objectives throughout the organization.

According to Swiss (1991) [22], the heart of a fullfledged MBOs process is the negotiation between a higher level manager and a subordinate manager of a performance contract. Figure 1 outline the five-step process for MBO. Each stage has particular challenges that need to be addressed for the whole system to work effectively. These steps are explained below.

\subsubsection{Set or Review Organizational Objectives}

MBOs start with clearly defined strategic organizational objectives which connected the organizational mission and vision. If the organization isn't clear where it's going, no one working there will be either.

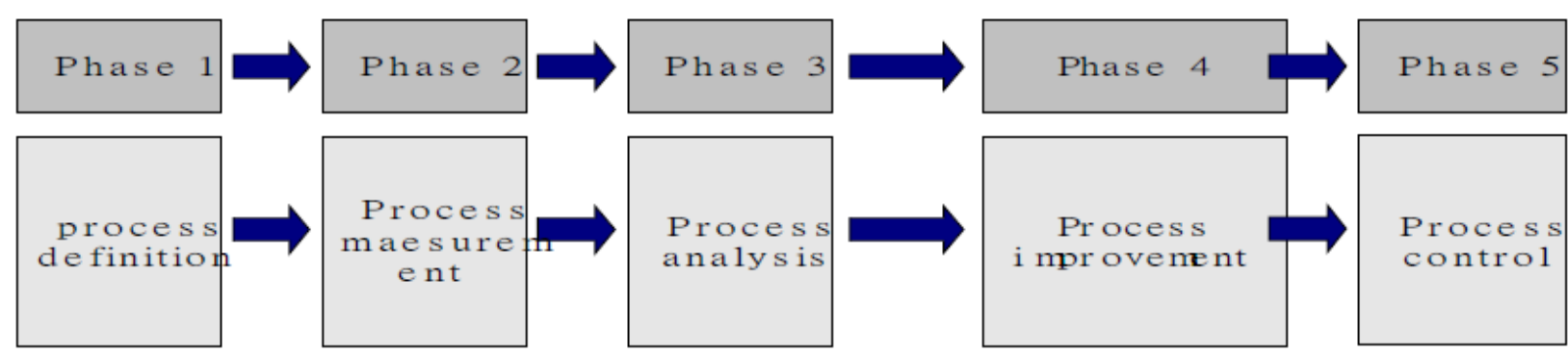

Figure 1. DMAIC methodology 


\subsubsection{Cascading Objectives Down to Employees}

To support the mission, the organization needs to set clear goals and objectives, which cascade down from one organizational level to the next until they reach everyone. MBOs need to establish clear targets and performance standards for each objective.

\subsubsection{Encourage Participation in Goal Setting}

The employees need to understand how their personal goals fit with the objectives of the organization. This is best done when goals and objectives at each level are shared and discussed, so that employees understands "why" things are being done, and then sets their own goals to align with these.

\subsubsection{Monitor Progress}

The monitoring system has to be timely enough so that issues can be dealt with before they threaten goal achievement. With the cascade effect, no goal is set in isolation, so not meeting targets in one area.

\subsubsection{Evaluate and Reward Performance}

MBOs are designed to improve performance at all levels of the organization. As goals have been defined in a specific, measurable and time-based way, the evaluation aspect of MBOs is relatively straightforward. Employees are evaluated on their performance with respect to goal achievement. All that is left to do is to tie goal achievement to reward, and perhaps compensation, and provide the appropriate feedback.

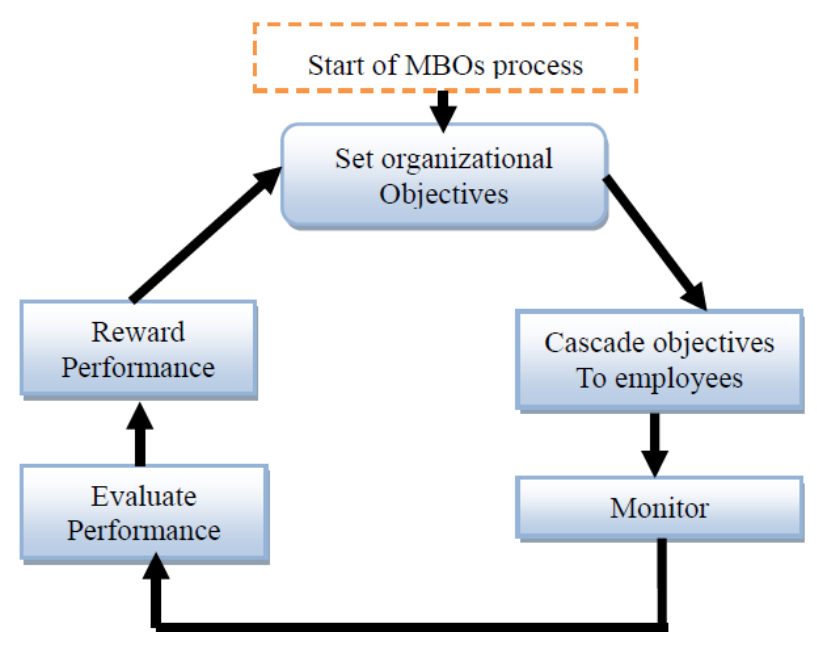

Figure 2. The five-step of MBO process

\section{Integrating Six Sigma with MBOs Framework}

Quality management transformation from MBOs to Six
Sigma is a continuous improvement, asking how widespread the use of MBOs process presently in Six Sigma system need to be, how full MBOs applications in Six Sigma system in terms of breadth and depth of coverage to be explored, and in what kinds of MBOs factors extended to be targeted by Six Sigma systems. The paper uses a case study to understand the significance of using MBOs process implement Six Sigma, and, via this empirical study, discover the contexts of MBOs process extension to Six Sigma.

Integrating Six Sigma with MBOs framework is based on three steps which is consensus, and action-planning period. The results of using MBOs improvement to implement Six Sigma are interpreted as following (Table 1).

\subsection{Consensus Step}

\subsubsection{Management Philosophy}

The organization must mold the Six Sigma vision and behaviors

\subsubsection{SWOT Analysis}

SWOT analysis that follows is a way for AIDC to create their unique set of strengths, weakness, opportunities and threats.

\subsubsection{Objective Setting}

Six Sigma are a project-driven and objective setting methodology, and is essential to identify project priorities that provide maximum financial benefits to the organization.

\subsection{Formulation Step}

\subsubsection{Strategy Formulation}

Formulation business strategy is to set up Six Sigma implementation.

\subsubsection{Steering Organization}

The employees of steering organization called Master Black Belts (MBBs), Black Belts (BBs) and Green Belts (GBs) to identify and execute projects.

\subsection{Action-planning Step}

\subsubsection{Project management + Action workout project}

Settings up measurements are that quantify the magnitude of the problem and used to set project goals and follow-up on progress.

\subsubsection{Evaluate Performance}

Organization maintains and increase high levels of quality via evaluating quality improvement performance.

Table 1. Integrating Six Sigma with MBOs framework

\begin{tabular}{|c|c|c|c|}
\hline Stage & 1 & 2 & 3 \\
\hline Step & Consensus & Formulation & Action-planning \\
\hline Aims & $\begin{array}{l}\text { to build the consensus of Six } \\
\text { Sigma development }\end{array}$ & $\begin{array}{l}\text { to formulate and implement Six } \\
\text { Sigma strategy }\end{array}$ & to integrate with Six Sigma project \\
\hline Process & $\begin{array}{l}\text { - Management philosophy } \\
\text { - SWOT analysis } \\
\text { - Objective setting }\end{array}$ & $\begin{array}{l}\text { - Strategy formulation } \\
\text { - Steering organization }\end{array}$ & $\begin{array}{l}\text { - Project management } \\
\text { - Action workout project } \\
\text { - Evaluate performance Evaluate performance }\end{array}$ \\
\hline
\end{tabular}




\section{An Empirical Study in Taiwan}

The Aerospace Industrial Development Corporation (AIDC), based in Taiwan, was established to produce the most advanced aircraft engine parts, and provide services related to the assembly, testing, maintenance and production planning. The AIDC Quality Management System has won approval from many leading aircraft and engine manufacturers, such as Boeing, Airbus, Bombardier, Bell, Sikorsky, General Electric Aircraft Engines (GEAE), Rolls-Royce, and Honeywell.

AIDC was reformed from a government-owned company into a private-own establishment since 2000 under the authority of the Ministry of Economic Affairs. Today as a market-oriented commercial entity, AIDC is working in tandem towards commercialization, privatization and globalization pressure. The reason for AIDC's to implement the Six Sigma system was to meet the requirements of its main buyers. Pursuant to the new company objectives of Six Sigma implementation, AIDC's business strategy has turned from products and services for solely military applications to a well-balanced diversified provider to both military and commercial markets.

AIDC participated in Raytheon GE Taiwan Executive Program (RGETEP) courses to learn implementation of Six Sigma at GE methodology. RGETEP offers courses in Six Sigma concepts including leadership Development at GE, work-out, change acceleration process, specialist seminar, communities of practice, strategy management.

Although the literature contains many accounts of successful applications of Six Sigma, few studies have examined the Six Sigma system in a Taiwanese context. In Taiwan there are a few enterprises that have implemented the Six Sigma system. However, there are two reasons why we selected select AIDC as a case study to consider.

\subsection{Six Sigma cannot be treated as yet another Stand-alone Activity.}

Six Sigma requires adherence to a whole philosophy rather than just the usage of a few tools and techniques of quality improvement. The AIDC Six Sigma implementation is clearly link to its business priorities, as reflected by business strategy and annual operating plan, and Six Sigma must be central to strategic drive of the firm.

\subsection{AIDC Six Sigma Initiatives Emphasize the Voice of the Customer}

AIDC Six Sigma initiatives place a strong emphasis on the voice of the customer by setting up a common language among the enterprises concerned, understanding customer demands and meeting customer requirements. In an attempt to keep pace with customer requirements, AIDC connects and analyzes customer information and are trying to make sense of it all information. By using customer information, AIDC's products, service and procedures meet customer requirements.

Table 2 display three steps to for AIDC Company to implement Six Sigma. After finishing courses in RGETEP, the upper management considered inviting RGETEP consulting to provide the Six Sigma system, and AIDC learn to the skills of Six Sigma system. Consequently, at step 3, AIDC managers make use of the company's solid infrastructure to develop Six Sigma from their existing MBO mechanisms by themselves. Three steps of consensus, formulation and action-planning are considered as follows. Although the three periods will be discussed independently, all of them are integrated and interrelated.

Table 2. Three steps of AIDC implement Six Sigma

\begin{tabular}{|c|c|c|c|}
\hline Step & 1 & 2 & 3 \\
\hline Approach & $\begin{array}{l}\text { The consulting to } \\
\text { provide the Six } \\
\text { Sigma system, } \\
\text { AIDC learn to the } \\
\text { skills of Six } \\
\text { Sigma system }\end{array}$ & $\begin{array}{l}\text { Implement to the } \\
\text { Six Sigma } \\
\text { system, the } \\
\text { consulting } \\
\text { support the Six } \\
\text { Sigma system }\end{array}$ & $\begin{array}{l}\text { The implement } \\
\text { to the Six } \\
\text { Sigma system } \\
\text { by themselves. }\end{array}$ \\
\hline
\end{tabular}

\subsection{Consensus Step}

\subsubsection{Management Philosophy}

AIDC transfer the government-owned company into a private-own establishment since 2000s. There are organizational and individual resistances where employees are experiences fear and emotional paralysis during privation process. It is important which identify the key resistance to Six Sigma initiative. AIDC improvement ways are to create management philosophy which from Task- oriented to profit-oriented. Figure 3 displays the AIDC's management philosophy for three dimensions.

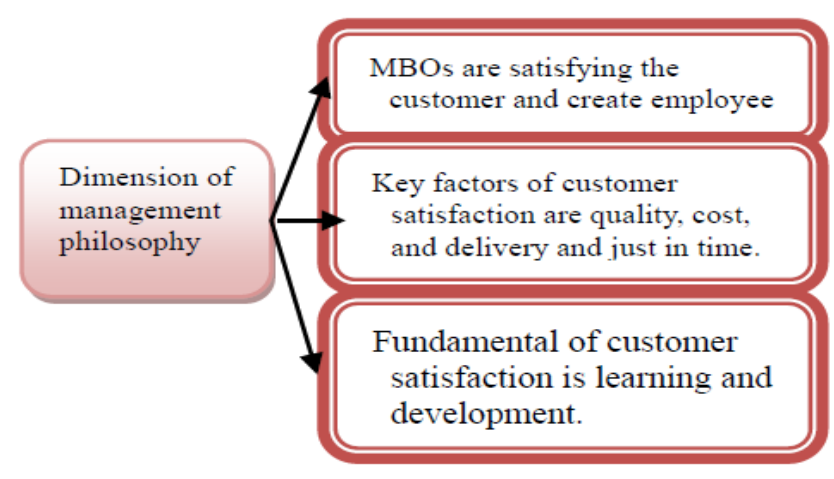

Figure 3. Transfer business management

\subsubsection{SWOT Analysis}

To clarify the need for Six Sigma in organization, the following questions must be confirmed: what will happen to AIDC if successfully implement Six Sigma? And what will happen to AIDC if don't successfully implement Six Sigma? The short and long-term threats are competitors improving through use of Six Sigma, to increase employee frustration and to reduce customer base. The short and long-term opportunities will improve profitability, to get greater productivity and increase employee development

\subsubsection{Objectives Setting}

AIDC demonstrates that effective project management is essential to the success of Six Sigma projects. The Six Sigma project index objectives include the customer cost reduction (Percent, \%), lead time reductions (Days), schedule adherence (Percent, \%), number of key suppliers, the establishment of a quality index (Parts per million defective, ppm). 


\subsection{Formulation Period}

\subsubsection{Strategy Formulation}

Strategy formulation which represents the ability to select, prioritize and remove barriers to Six Sigma projects in a matter that integrates planning, management and accountability. Figure 4 displays that the AIDC business goals which include on time delivery, inventory reduction, quality, to productivity and cost.

\subsubsection{Steering Organization}

AIDC’s Six Sigma involves highly trained employees called MBBs, BBs and GBs who have undergone rigorous statistical training and lead teams in identifying and executing projects. Decisions on steering organizational structure are driven by Six Sigma objectives, implementation plan, budget, and existing staff and resources. Figure 5 show that the cluster leader of improvement team is a MBBs which a certificated Six Sigma training. The sub-leader is BBs which come from cross-department such as productions department and quality department.

\subsection{Action Planning Period}

\subsubsection{Project Management}

AIDC demonstrates that effective project management is essential to the success of Six Sigma projects. Figure 6 display that the Six Sigma quality policy divides into the quality assurance and customer satisfaction. Each department and section of project management which represents the ability to select, prioritize and remove barriers to Six Sigma projects in a matter that integrates planning, management and accountability.

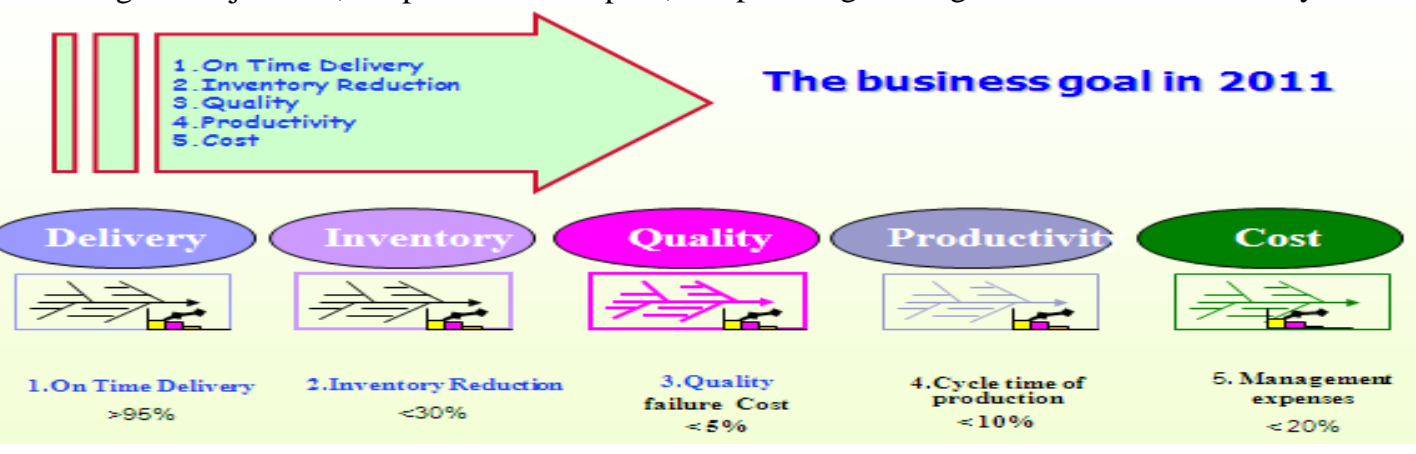

Figure 4. Six Sigma projects and business objectives

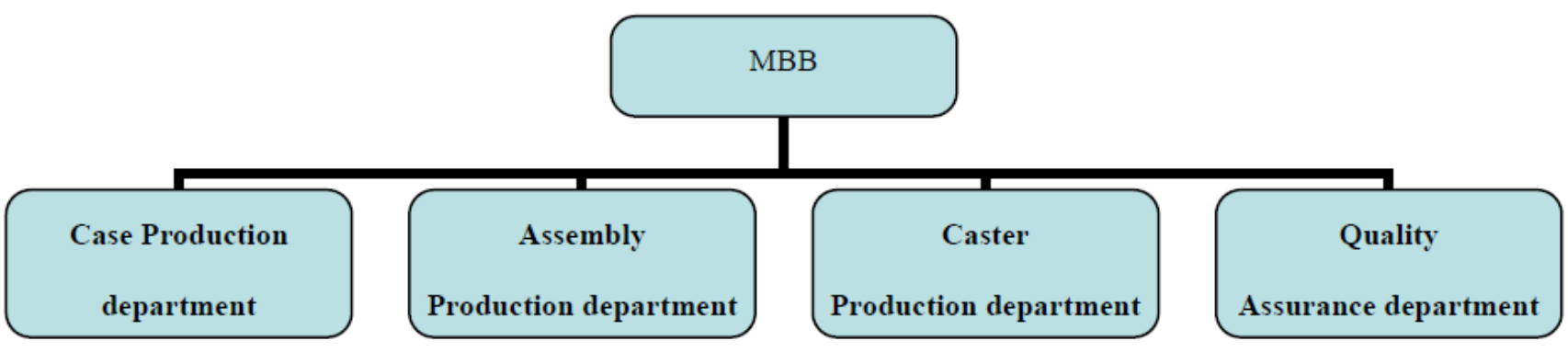

Figure 5. The MBB approach of steering organization
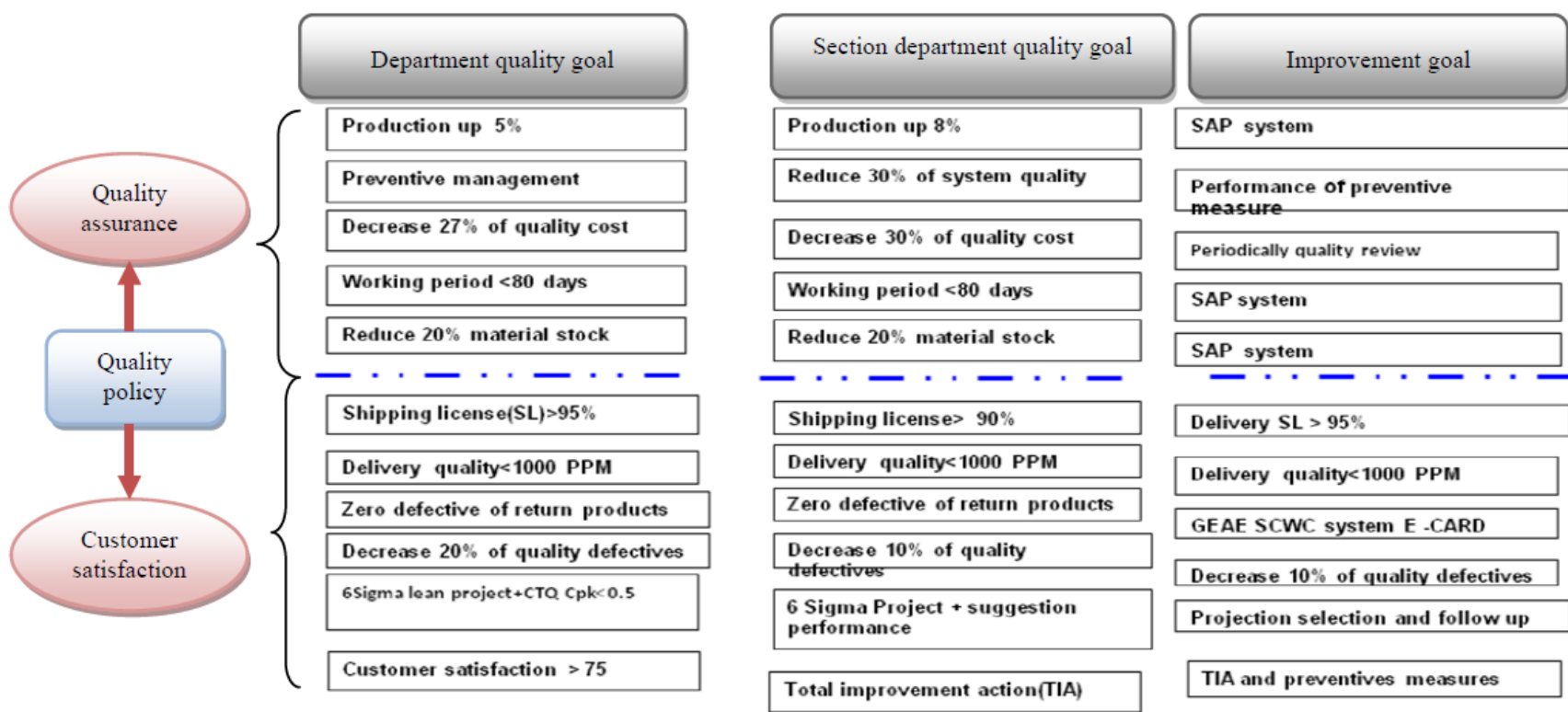

Figure 6. Quality policy and goals 


\subsubsection{Action plan}

AIDC training schedule involves four months of training, writing three mid-term project reports, and applying and completing the Six Sigma project schedule.

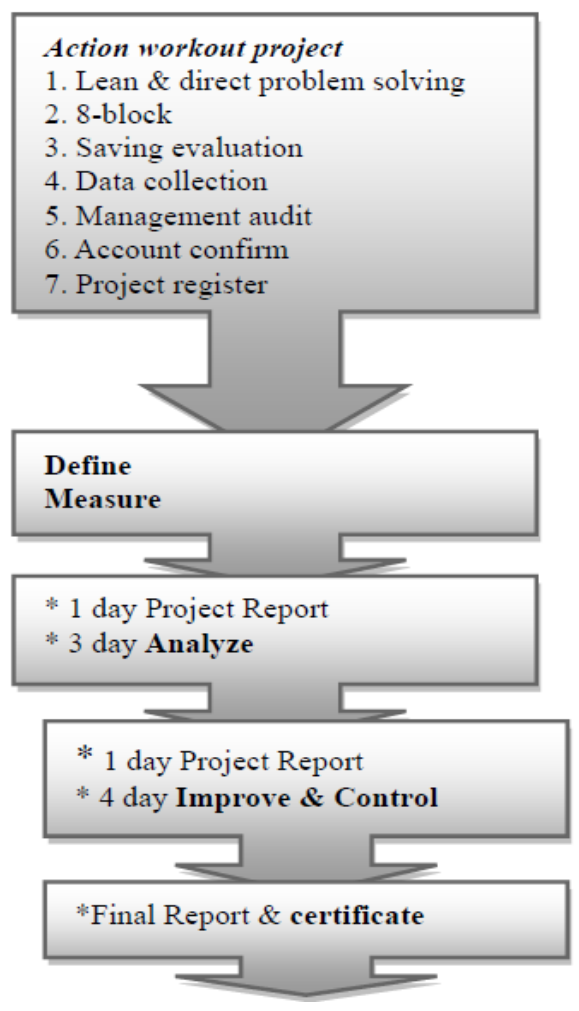

Figure 7. Six Sigma action plan

\subsubsection{Performance Audit}

AIDC establish final inspection procedure and inspector learning organization. The final inspection document slips the mapping of planning schedule and inspector grouping which confirm the quality assurance. Team members of inspector group include QC Manager, QC Engineer, foreman and inspector. The courses for inspector learning include how to management instruction, Six Sigma skills and support, how to transfer Six Sigma experience and on the job training to verify inspector Capability.

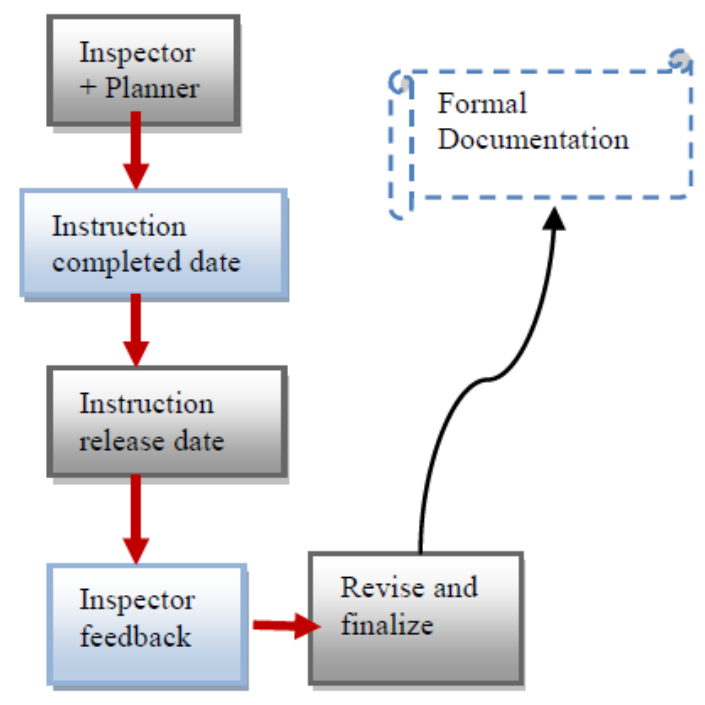

Figure 8. Process of final inspection procedure
Regarding the performance of quantitative outcome (shown in Table 3), AIDC business performance has improved each year from 2006 to 2010. Ccustomer cost reduction has decreased from 2007 to 2010. Lead time reductions have sharply reduced to 35 days. Sschedule adherence performance upgrades 95\% improvements, and decreasing Quality defectives (ppm) from 2006 to 2010.

Table 3. Performance of implementing Six Sigma

\begin{tabular}{|c|c|c|c|c|c|}
\hline Item / Year & 2006 & 2007 & 2008 & 2009 & 2010 \\
\hline Customer cost reduction (\%) & $6 \%$ & $6 \%$ & $5 \%$ & $5 \%$ & $4 \%$ \\
\hline Lead time reductions (days) & 180 & 100 & 60 & 40 & 35 \\
\hline Schedule adherence \% & 70 & 75 & 80 & 95 & 95 \\
\hline Number of key suppliers & 230 & 200 & 200 & 40 & 10 \\
\hline Quality defectives (ppm) & 6500 & 6200 & 2800 & 500 & 300 \\
\hline
\end{tabular}

\section{Conclusion and Implication}

\subsection{Conclusion}

\subsubsection{Build the Basic MBOs Fundamental for Implement Six Sigma}

The Six Sigma implementation will not achieve expected performance if there are some organizational and individual resistances. Business position transfers the government-owned company into a private-own such as AIDC case, they need to overcome organizational resistance via building organizational consensus, then implement SWOT analysis to develop business objective. AIDC mold the Six Sigma vision via participating in Raytheon GE Taiwan Executive Program to learn Six Sigma implementation. They take three steps to implement Six Sigma which from learn to the skills of Six Sigma system to implement Six Sigma by themselves. Management philosophy is to be set-up before implementing Six Sigma system.

\subsubsection{Implementing Six Sigma Strategies via Steering Organization Structure}

Judged from the AIDC case of implementing Six Sigma quality history, the Six Sigma system is just not a skill approach, but also business strategy process. The AIDC formulate Six Sigma strategy development based on MBOs mechanisms which by aligning department goals and subordinate section objectives throughout the organization. Steering organization takes the cluster approach to build the cross-department of improvement team. The cluster approach of steering organization integrate different department to solve the rooted problem.

\subsubsection{Integrate Action Workout Project with Project Management}

If the organization want to the MBO with Six Sigma implementation can achieve business performance, the action plan must down through the bottom line. Action plan on the bottom line also needs to have a detailed improvement project. The AIDC's improvement plan on the Six Sigma projects are to improve step by step which from confirm on the requirements of improvements point at the first and audit and evaluate improvement performance 
at the final step. AIDC also implement training courses to learn how to be management instruction, what Six Sigma skills and support, how to transfer Six Sigma experience and implement on the job training to confirm the quality assurance.

\subsection{Implications}

From AIDC's experience, the following are the key fundamentals that must be considered when using MBO implement Six Sigma

\subsubsection{Value-oriented}

Integrated MBO with Six Sigma activities should be chosen based on how valuable it is to the organization, how badly the process is broken, and what the impact upon the organization would be if the process were improved. We should choose what process we want to improvement, and thus can achieve expected business performance.

\subsubsection{Customer-oriented}

Regarding the experience of AIDC, they have achieved continuous improvements using MBO mechanisms. AIDC have made competitive changes based on the requirements of outsourcing buyers, and the related need to adapt quickly to meet customer requirements. However, AIDC has not abandoned MBOs strategy, but has integrated its mechanisms with the Six Sigma approach to gain a new competitive advantage.

\subsubsection{Integration-oriented}

MBO is prime component of Six Sigma, and the author finds that AIDC added a Six Sigma program to their business strategy system, giving them almost all of the elements of MBO: current business strategy system + Six Sigma project management $=$ MBO. The combination of the current business strategy process and the Six Sigma provide the organization with the best overall value. Based on this formula, $\mathrm{MBO}$ as an integrated quality program remains prevalent in modern industry, and the example of AIDC suggests one way of extending this kind of formula to incorporate a strategic element.

\section{References}

[1] Sandholm, L. and Sorqvist, L. "12 requirements for Six Sigma success,” Six Sigma Forum Magazine, 2(1), 17-22. 2002.
[2] Yang, Ching-Chow. "An integrated model of TQM and GE Six Sigma," International Journal of Six Sigma and Competitive Advantage, 1 (1), 97-111. 2004.

[3] Kumar M, Antony J, Antony F et al. "Winning customer loyalty in an automotive company through Six Sigma: a case study," Quality and Reliability Engineering International, 23(7), 849-866. 2007.

[4] Krishna R, Dangayach G, Motwani J and Akbulut A. "Implementation of Six Sigma Approach to Quality Improvement in a Multinational Automotive Parts Manufacturer in India: A Case Study," International Journal of Services and Operations Management, 4(2), 264-276, 2008.

[5] Azis, Yudi\& Osada, Hiroshi. "Innovation in management system by Six Sigma: an empirical study of world-class companies," International Journal of Lean Six Sigma, 1(3), 172-190, 2010.

[6] Drucker, P. F, the Practice of Management, Harper \& Brothers, New York, 1954.

[7] Pande, P. S., Neuman, R. P. and Cavanagh, R.R. The Six Sigma Way-How GE, Motorola and other Top Companies are honing their Performance, McGraw-Hill, New York, 2000.

[8] Snee, R. D. "Dealing with the Achilles' heel of Six Sigma Initiatives,” Quality Progress, 34(3), 66-72. 2001.

[9] Pearson, T. A. "Measure for Six Sigma Success," Quality Progress, 34(2), 35-40. 2001.

[10] Bañuelas, R. and Antony, J. "Critical success factors for the successful implementation of Six Sigma projects in organizations," The TQM Magazine, 14(2), 92-99. 2002.

[11] Chatterjee, A. "Innovating growth through Six Sigma: a strategic approach for combining robustness with flexibility," Global Journal of Flexible Systems Management, 4(3), 33-37. 2003.

[12] Antony, J., Kumar, M. and Madu, C.N. "Six Sigma in small and medium size UK manufacturing enterprises," International Journal of Quality \& Reliability Management, 22(8), 860-874. 2005.

[13] Firka, D. "Six Sigma: an evolutionary analysis through case studies,” TQM Journal , 22(4) , 423-434. 2010.

[14] Prashar, A. "Adoption of Six Sigma DMAIC to reduce cost of poor quality," International Journal of Productivity and Performance Management, 63(1), 103-126, 2014.

[15] Harry, M. and Schroeder, R. Six Sigma: the Breakthrough Management Strategy Revolutionalizing the World's Top Corporations, Currency/Doubleday, New York, 2000.

[16] Hammer, M. and Goding, J. "Putting Six Sigma in perspective," Quality, 40(10), 58-63. 2001.

[17] Jirasukprasert et al. "A Six Sigma and DMAIC application for the reduction of defects in a rubber gloves manufacturing process," International Journal of Lean Six Sigma, 5(1), 2-21, 2014.

[18] Byrne, G. "Ensuring Optimal Success with Six Sigma Implementations,” Journal of Organizational Excellence, 22(2), p. 43-50. (Spring 2003).

[19] Simpson, J.A. "Management by objective for appraisal firms," The Appraisal Journal , 61(3), 380-386. (1993).

[20] Robbins, S.P. Managing Today, Prentice-Hall International, Upper Saddle River, New Jersey, 1997.

[21] Chen, C.C. an Chang, W.L. "Total-costs based NPD performance measurement," ASQ World Conference on Quality and Improvement Proceedings, in Minneapolis, MN, 457-469. 2004.

[22] Swiss, J. E. "Establishing a management system: the interaction of power shifts and personality under Federal MBO," Public Administration Review, 43(3), 238-245. 1983. 